\title{
Spatial structure of woody cover affects habitat use patterns of ocelots in Texas
}

\author{
Jason V. Lombardi ${ }^{1}$ (D) Michael E. Tewes $^{1} \cdot$ Humberto L. Perotto-Baldivieso ${ }^{1} \cdot$ Jose M. Mata $^{1,2} \cdot$ Tyler A. Campbell $^{3}$
}

Received: 13 August 2019 / Accepted: 28 April 2020 / Published online: 27 May 2020

(C) The Author(s) 2020

\begin{abstract}
About $80 \%$ of the known breeding population of ocelots (Leopardus pardalis) in the USA occurs exclusively on private ranches in northern Willacy and Kenedy counties in South Texas. These private ranches support several large contiguous undisturbed patches of thornscrub, which is preferred by ocelots. Past studies have indicated ocelots in South Texas select for woody patches that contain extremely dense thornscrub (i.e., 95\% canopy cover and $85 \%$ vertical cover) and require large patches of woody cover to survive. Landscape metrics have been used to explain ocelot habitat use in fragmented areas, but their application in lessfragmented rangelands is lacking. From 2011 to 2018, we used camera traps on the East Foundation's El Sauz Ranch to assess seasonal habitat use of ocelots relative to landscape structure, configuration, and complexity and other site-level factors in South Texas. Seasonal habitat use and detection were positively influenced by larger mean patch area and lower landscape shape index values. We also observed ocelots were less likely to be detected during periods of drought and exhibited a seasonal trend in detection. Ocelots used woody patches that were larger and more regularly shaped, indicating a preference for areas with a lower degree of fragmentation across the study area. As patches become larger, they will coalesce over time and form larger woody aggregates, which will promote ocelot habitat use. Brush management needs to be strategic as patch area and shape index are a limiting factor to promote ocelot habitat use on working rangelands in South Texas. These results demonstrate the ability to use landscape metrics to discern the effects of spatial structure of vegetation communities relative to ocelot occupancy parameters.
\end{abstract}

Keywords Landscape metrics $\cdot$ Leopardus pardalis $\cdot$ Landscape shape index $\cdot$ Mean patch area $\cdot$ Private lands

Assessing landscape-level changes in landscape structure and determining the effects of historic or current fragmentation can aid in defining conservation strategies needed for

Communicated by: Krzysztof Schmid

Electronic supplementary material The online version of this article (https://doi.org/10.1007/s13364-020-00501-2) contains supplementary material, which is available to authorized users.

Jason V. Lombardi

Lombardijv@gmail.com

1 Caesar Kleberg Wildlife Research Institute, Texas A\&M UniversityKingsville, 700 University Blvd, MSC 218, Kingsville, TX 78363, USA

2 East Foundation, 200 Concord Plaza Drive, Suite 410, San Antonio, TX 78216, USA

3 Present address: Department of Ecosystem Science and Management, College of Agriculture and Life Sciences, Texas A\&M University, 600 John Kimbrough Blvd, Suite 510, College Station, TX 77843, USA recovering carnivore populations (Jackson et al. 2005; Zemanova et al. 2017). Throughout much of the world, human disturbance such as oil and gas exploration, deforestation, large- and small-scale agriculture and livestock production, and urbanization has had extensive effects on mammalian carnivores and other species (Sanderson et al. 2002; McKinney 2008). Unlike protected tracts of land such as national parks and wildlife refuges, private lands (i.e., rangelands, farms, forest plantations) may not be immune to changes in landscape structure, composition, or complexity and could become an impediment to wildlife use over time (Lombardi et al. 2018). Ninety percent of threatened and endangered species exist on private lands in the USA (Scott et al. 2001).

Among mammals, medium-large carnivores face the highest potential extinction risks due to higher trophic levels, lower population densities, and large home ranges (Cardillo et al. 2004). Within the family Felidae, small-medium-sized felids (e.g., ocelot (Leopardus pardalis), margay (Leopardus weidii), and marbled cat (Pardofelis marmorata)) are generally 
understudied compared to the big cats (Grassman et al. 2005; Nagy-Reis et al. 2017; Anile et al. 2019). Through the use of camera traps, researchers have now been able to peel back the curtain and gain a stronger understanding of how these lesser felids respond to natural and anthropogenic factors that may impact patterns of habitat use, population density, and occupancy (Jackson et al. 2005; Singh et al. 2014; Gómez-Ramírez et al. 2017; Anile et al. 2019). Statistical approaches like occupancy modeling have become a useful technique for discerning species occurrence or habitat use at different temporal and spatial scales (Wang et al. 2019). This statistical approach combined with robust long-term camera trap monitoring datasets, landscape metrics, and other site-level factors can aid in elucidating potential thresholds of habitat use and help guide recovery strategies, land stewardship, and management decisionmaking (Crooks 2002; Zemanova et al. 2017).

The ocelot (Leopardus pardalis) is a medium-sized neotropical felid $(6.6-18.6 \mathrm{~kg})$, with an extensive geographic range stretching from northern Argentina to extreme southern Texas (Haines et al. 2006; Hunter 2019).

Ocelots are listed on Appendix I on the Convention on International Trade in Endangered Species of Wild Fauna and Flora (CITES) due to habitat loss and fragmentation, vehicle collisions, loss of genetic diversity, killing due to livestock depredation, and heavy hunting in the early-mid 1900s (Haines et al. 2005a; Janečka et al. 2011, 2014, 2016; IUCN 2020). Ocelots are listed as Endangered in the USA and Vulnerable in Brazil, Colombia, and Argentina (Hunter 2019; IUCN 2020).

Ocelots inhabit a variety of vegetation communities including but not limited to Pine (Pinus spp.)-oak (Quercus spp.) and oak woodlands, semi-arid thornscrub, subtropical and tropical broadleaf forests, and gallery forests (Horne et al. 2009; Gomez-Ramirez et al. 2017; Paolino et al. 2018; Satter et al. 2019; Wang et al. 2019). Ocelots have been documented in open grasslands and flood plains, but studies have linked highest indices of ocelot occurrence to areas of dense canopy cover (Emmons 1988; Shindle and Tewes 1998; Harveson et al. 2004; Horne et al. 2009; Wang et al. 2019). Ocelots are solitary, semi-arboreal, and nocturnal predators that prey on small mammals, birds, and reptiles across their range (Booth-Binczik et al. 2013; Hunter 2019). Ocelot ecology has increasingly become more understood over the last 35 years with the advent of camera trapping, especially in Central and South America (Massara et al. 2015, 2018; Paolino et al. 2018; Satter et al. 2019; Wang et al. 2019); however, there is a paucity in similar data in the USA (Haines et al. 2006; Lombardi et al. 2020a).

In the USA, $<80$ ocelots exist in two isolated breeding populations in Kenedy, Willacy, and Cameron counties in southern Texas (Haines et al. 2006; Janečka et al. 2014, 2016; Leonard et al. 2020). The larger ranch population exists on private working lands in Kenedy and northern Willacy counties and is home to about $80 \%$ of ocelots in Texas. These working lands also have the largest patches of thornscrub and live oak (Quercus virginiana) forest remaining in the region (Navarro-López 1985; Tewes 2017; Leonard et al. 2020; Lombardi et al. 2020b). The smaller Refuge population occurs in and around the Laguna Atascosa National Wildlife Refuge in eastern Cameron County (Haines et al. 2005a, b; Tewes 2017).

The majority of ocelot habitat studies in Texas to date have occurred on Laguna Atascosa National Wildlife Refuge, an area surrounded by a matrix of agriculture, highspeed roadways, and encroaching urban areas (Harveson et al. 2004; Haines et al. 2005a, b; Laack et al. 2005; Jackson et al. 2005; Horne et al. 2009). Jackson et al. (2005) reported that ocelots in these areas strongly select for areas that have greater shape index values, contain more edge, and are more isolated, indicating a greater degree of fragmentation in these areas. Unfortunately, however, this higher degree of fragmentation has contributed to severe genetic erosion over the last 60 years (Janečka et al. 2011, 2014, 2016). Though studies have been conducted examining ocelot habitat use patterns in fragmented landscapes, habitat use patterns in the larger working rangelands where there are likely larger patches and a greater degree of spatial heterogeneity in the structure, configuration, and complexity of woody cover are poorly known (Lombardi et al. 2020b).

We conducted this present study to provide valuable information regarding ocelot habitat relationships (e.g., effects of composition, configuration, and landscape complexity) within woody communities on working rangelands in South Texas. The results will help formulate recovery and conservation strategies for ocelots and guide habitat management plans. For this study, we monitored camera traps over 7 years to examine seasonal patterns of ocelot habitat use relative to landscape structure, configuration, and complexity and other site-level factors. Due to the absence of urban development in our study site, we expected ocelots to use large forested habitats on working rangelands differently than compared to other fragmented areas of South Texas. We propose the following hypotheses: (1) site-level metrics (e.g., increased in canopy cover, horizontal cover) will positively influence habitat use patterns of ocelots, (2) spatial structure of woody cover will positively influence what areas ocelots are likely to use, and (3) ocelots are less likely to be detected during periods of drought than during wet periods.

\section{Methods}

\section{Study area}

We conducted this study on the East Foundation's El Sauz Ranch (hereafter, El Sauz) in Willacy and Kenedy counties in southern Texas (Fig. 1). The East Foundation managed this 
Fig. 1 Locations of 28 camera stations on the East Foundation's El Sauz Ranch in Willacy and Kenedy counties in South Texas, used to examine ocelot

(Leopardus pardalis) habitat use from 1 May 2011 to 31

March 2018

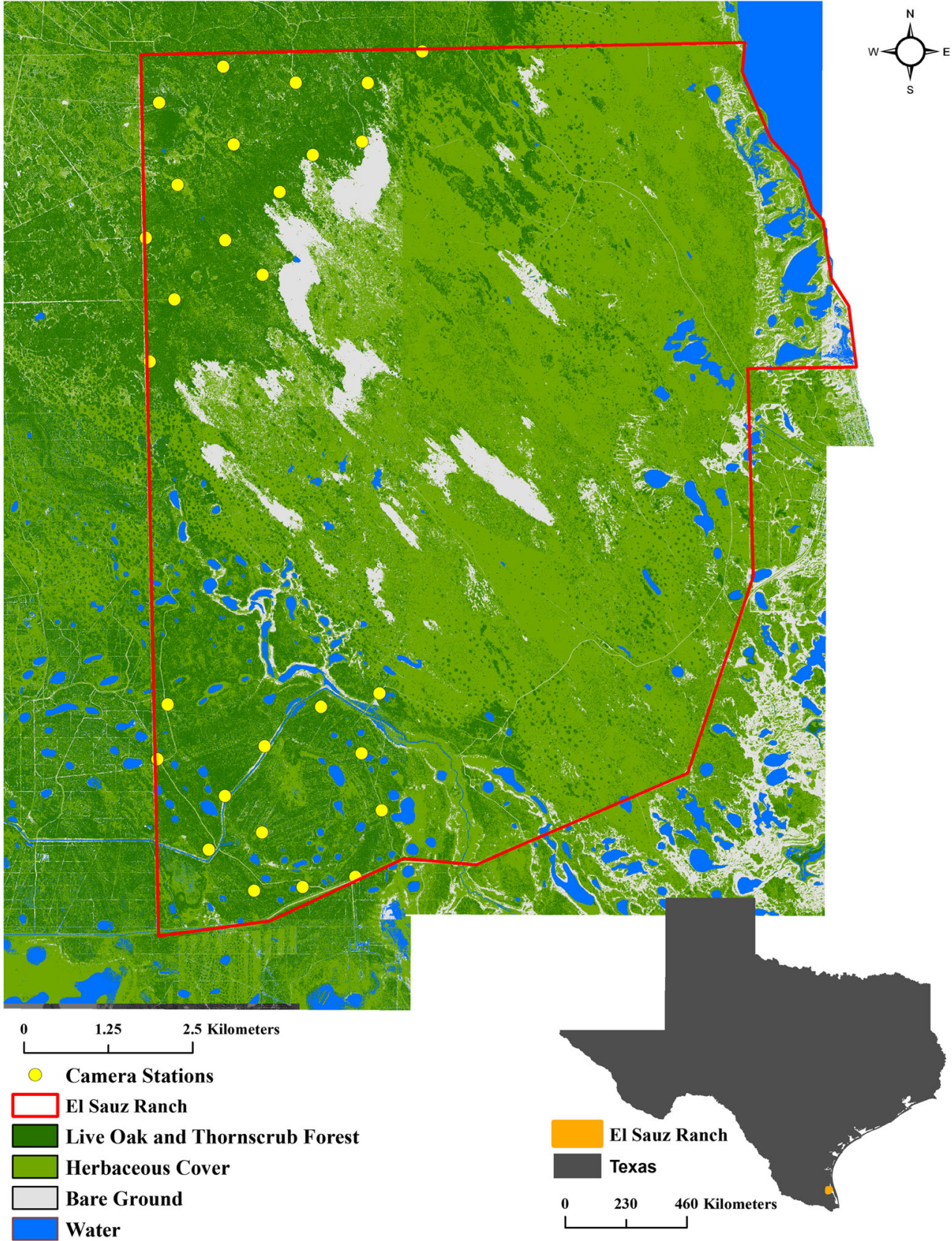

large ranch $\left(113 \mathrm{~km}^{2}\right)$ for cattle, wildlife, and conservation (Leonard et al. 2020, Lombardi et al. 2020a). The southern boundary of the ranch was adjacent to Texas Farm-to-Market 186, a high-speed $(120 \mathrm{kph})$ state roadway. Large private working rangelands bordered the northern and western boundaries, and the eastern boundary was next to the Laguna Madre and the coastal town of Port Mansfield, Texas. Land cover composition included herbaceous cover (e.g., coastal prairie, palustrine emergent wetland, and pasture-grasslands), woody cover (e.g., thornshrub, honey mesquite (Prosopis glandulosa) and live oak forests, and palustrine emergent wetlands), bare ground (e.g., caliche roads and inland dunes), and water (e.g., saline lagunas and anthropogenic ponds and canals). Woody vegetation occurring in these areas also included American beautyberry (Callicarpa americana), lotebush (Ziziphus obtusifolia), lime prickly ash (Zanthoxylum fagara), huisache (Acacia farnesiana), spiny hackberry (Celtis pallida), crucita (Eupatorium odoratum), desert olive (Forestiera angustifolia), Berlandier's wolfberry (Lycium berlandieri), snake-eyes (Phaulothamnus spinescens), and brasil (Condalia hookeri) (Shindle and Tewes 1998; Leslie 2016; Lombardi et al. 2020a). El Sauz was located on the convergence of three eco-regions: the Laguna Madre Barrier Islands and Coastal Marshes, Coastal Sand Plain, and the 
Lower Rio Grande Valley (Bailey and Cushwa 1981) and has a subtropical semi-arid climate $\left(10-36{ }^{\circ} \mathrm{C}\right)$ with episodic drought (Norwine and Kuruvilla 2007).

\section{Camera surveys}

From 1 May 2011 to 31 March 2018, we conducted camera surveys on the El Sauz Ranch as a part of a long-term ocelot population monitoring project. We used a systematic, gridbased sampling method with a randomized point within each grid cell (Meek et al. 2014; Lombardi et al. 2020a). We maintained a minimum of $1 \mathrm{~km}$ spacing between all sampling locations (i.e., camera stations), as required for ocelot camera surveys by the USA Fish and Wildlife Service (Permit Number permit TE822908-0). This spacing was based on historic ocelot telemetry data collected in the early $2000 \mathrm{~s}$ (Lombardi et al. 2020a). We focused camera grids in areas of live oak and thornscrub forest in the northwestern (15 camera stations; $15 \mathrm{~km}^{2}$ ) and southwestern (13 camera stations; $13 \mathrm{~km}^{2}$ ) areas of El Sauz. These areas were selected due to ocelot occurrence being strongly tied to these vegetation communities (Navarro-López 1985; Shindle and Tewes 1998; Horne et al. 2009). At each randomized location, we established a camera station with two cameras in areas within or immediately adjacent to thornscrub or live oak patches. To avoid biasing our detection rates, we did not use bait or lures at the camera station to ensure ocelot behavior was not affected (Lombardi et al. 2020a). At each camera station, there were two Cuddeback ${ }^{\circledR}$ Expert Scouting Cameras and Cuddeback ${ }^{\circledR}$ $\mathrm{X}$-Change Color cameras (Non-Typical Inc., Green Bay, Wisconsin, USA) with a 30-s delay between photographic events. Cameras were attached to trees or wooden stakes $0.5 \mathrm{~m}$ above ground and offset $1-2 \mathrm{~m}$ to enable individual identification of individuals for population monitoring (Satter et al. 2019).

\section{Landscape structure and site-level metrics}

Landscape and site-level variables were quantified to examine their influence on seasonal habitat use (Table 1). Site-level biotic variables examined included percent canopy cover, percent horizontal cover, canopy height (m), and shrub height (m). We marked the center of each camera station and estimated percent canopy cover using a Geographic Resource Solutions ${ }^{\circledR}$ (Geographic Resource Solutions, Arcata, CA) convex densitometer at $5 \mathrm{~m}$ in four cardinal directions and the center; the five values were then averaged for each station. We defined a categorical canopy cover variable based on open $(<25 \%)$, mixed $(25-75 \%)$, and closed canopies $(>75 \%)$ at each camera station (Lombardi et al. 2020a). We used the point-intercept method to estimate mean horizontal cover at three different height profiles $(0.0-0.5,0.5-1.0$, and 1.0 $2.0 \mathrm{~m})$ using a polyvinyl-chloride cover pole $(2 \times 3 \mathrm{~m})$ marked at $0.5 \mathrm{~m}$ heights. We measured the height of each the lower shrub canopy and upper overhead canopy at each camera station at the center of each camera station (Horne et al. 2009).

To assess the influence of landscape structure, configuration, and complexity on ocelot habitat use, we conducted an unsupervised land cover classification of the El Sauz Ranch using 2014 1-m imagery from the National Agriculture Imagery Program in ERDAS IMAGINE (Hexagon Geospatial, Norcross, GA, USA. Following Lombardi et al. (2020a), land cover classes were based on four broad categories: woody cover (i.e., mesquite, huisache, thornscrub, and live oak forest, and woody areas within palustrine emergent wetlands), bare ground (i.e., inland dunes, barren ground, levees, paved and caliche roads), herbaceous (i.e., grasslands, Texas Gulf Coast Prairie, and herbaceous cover within palustrine emergent wetlands and along caliche roads), and water (i.e., lagunas, canals, and anthropogenic ponds). To assess our classification, we collected 629 ground-truth points in June and September 2016 using a Trimble ${ }^{\circledR}$ Geo 7 Series Handheld Computer with $1 \mathrm{~m}$ precision and Trimble Nomad ${ }^{\circledR} 1050$ Series Handheld Computer with GBSS $1 \mathrm{~m}$ precision (Trimble Navigation, Ltd., Sunnyvale, CA, USA). We then used a confusion matrix to compare visually observed field data and the classified imagery (Congalton 1991) achieving an overall accuracy of $85.1 \%$. Using the classified imagery, we placed a 500-m buffer around each camera site (sampling unit) and we examined six class-level metrics to quantify the spatial structure of woody and herbaceous cover types using Fragstats 4.2 (McGarigal et al. 2015): patch density (PD; number of patches/100 ha), landscape shape index (LSI), mean patch area (MPA; ha), percent landscape (PLAND; \%), Euclidean distance to nearest neighbor (ENN; $\mathrm{m}$ ), and edge density (ED; $\mathrm{m} / \mathrm{ha}$ ) (Perotto-Baldivieso et al. 2011; Zemanova et al. 2017; Lombardi et al. 2020a).

\section{Occupancy modeling}

We examined the influence of landscape structure, configuration, and complexity on detectability and multi-season habitat use patterns of ocelots using a simple multi-season occupancy model in program PRESENCE (v 12.1, MacKenzie et al. 2018). Because ocelot's home ranges in this region exceed that of the sampling unit (Leonard 2016), we will interpret true occupancy in this context as habitat use (MacKenzie et al. 2005, 2018). Before initial model construction, we used Pearson's correlation analysis to examine correlation(s) among site-level and landscape-level covariates. Non-correlated variables $(|r|<0.70)$ were grouped and combined based on 12 a priori hypotheses, which were based on the ecology of ocelots in Texas (Supplementary material Table 1). Continuous variables were normalized within the program PRESENCE (Murphy et al. 2017; Lombardi et al. 2018). 
Table 1 Multi-season occupancy model selection used to estimate ocelot (Leopardus pardalis) detection $(p)$ and seasonal habitat use $(\psi)$ across 28 camera stations on the East Foundation's El Sauz Ranch, Willacy and Kenedy counties, Texas

\begin{tabular}{|c|c|c|c|c|}
\hline Model & $\mathrm{AIC}_{\mathrm{c}}$ & $\Delta \mathrm{AIC}_{\mathrm{c}}$ & $\omega$ & $\mathrm{K}$ \\
\hline$\psi(W M P A+W L S I) p(S E A S O N+W M P A+W L S I+P D S I)$ & 3808.01 & 0.00 & 0.7659 & 20 \\
\hline$\psi($ WPLAN + WPD + WLSI + ENN) p (SEASON + WMPA + WLSI + PDSI) & 3810.68 & 2.67 & 0.1912 & 22 \\
\hline$\psi($ ShrubHt + CanopyHt + Canopy Cover + HZ Cover $)$ p (SEASON +WMPA + WLSI + PDSI $)$ & 3814.22 & 6.21 & 0.0326 & 22 \\
\hline$\psi($ WPD + WPLAN + ENN) p (SEASON + WMPA + WLSI + PDSI $)$ & 3816.95 & 8.93 & 0.0083 & 21 \\
\hline$\psi($ Canopy Cover + HZ Cover) $\mathrm{p}($ SEASON + WMPA + WLSI + PDSI $)$ & 3821.95 & 13.94 & 0.0007 & 20 \\
\hline$\psi($ ShrubHt + CanopyHt) p (SEASON + WMPA + WLSI + PDSI $)$ & 3822.95 & 14.94 & 0.0004 & 20 \\
\hline$\psi($ HPLAN + HPD + HENN) p (SEASON + WMPA + WLSI + PDSI $)$ & 3822.97 & 14.96 & 0.0004 & 21 \\
\hline$\psi($ ShrubHt + CanopyHt + Canopy Cover) p (SEASON + WMPA + WLSI + PDSI $)$ & 3824.40 & 16.39 & 0.0002 & 21 \\
\hline$\psi(.) \mathrm{p}(\mathrm{SEASON}+\mathrm{WMPA}+\mathrm{WLSI}+\mathrm{PDSI})$ & 3826.05 & 18.03 & 0.0001 & 18 \\
\hline$\psi($ Open Canopy Cover + Dense Canopy Cover $)$ p (SEASON + WMPA + WLSI + PDSI $)$ & 3826.05 & 18.04 & 0.0001 & 20 \\
\hline$\psi($ WPLAN + HPLAN) p (SEASON + WMPA + WLSI + PDSI $)$ & 3826.58 & 18.57 & 0.0001 & 20 \\
\hline
\end{tabular}

The prefix "W" refers to woody cover, the prefix "H" refers to herbaceous cover, mean patch area (MPA; ha), Landscape Shape Index (LSI), Palmer Drought Severity Index (PDSI), Percent of Natural Landscape (PLAN; \%), Patch Density (PD; patches per 100 ha), Euclidean Nearest Neighbor (ENN; $\mathrm{m})$, height of shrubs $<2 \mathrm{~m}$ (ShrubHt), height of overhead canopy $>2 \mathrm{~m}$ (CanopyHt), mean canopy cover (\%, canopy cover), mean horizontal cover ( $\%, \mathrm{HZ}$ cover), $<25 \%$ canopy cover (open canopy cover), and $>75 \%$ canopy cover (dense canopy cover). The most supported model is italicized.

To build our habitat use models, we defined a 7-day (weekly) occasion, where the first ocelot detection within a given week was marked as detected that week. We defined seasons based on ocelot biology and climate criterion. Unlike bobcats (Lynx rufus), ocelots in Texas are a-seasonal breeders, having been documented giving birth to young kittens all year and young are not weaned until 18 months (Laack et al. 2005). There are also no studies to support seasonal trends in mortality rates in this region. South Texas is also marked by a semiarid subtropical climate with summer temperatures often $>$ $30{ }^{\circ} \mathrm{C}$ and cooler periods of $<20{ }^{\circ} \mathrm{C}$. Due to the biology of ocelots (Hunter 2019; IUCN 2020) and the difference in seasonal temperatures, we partitioned seasons based on the monthly average temperature for the region (National Oceanic Atmospheric Administration: National Climate Database, https://www.ncdc.noaa.gov/cdo-web/datasets, accessed 17 March 2017) over the sampling period (hotseason $\left[29^{\circ} \mathrm{C}\right]$ : 1 May to 30 September; cool-season $\left[18.4^{\circ}\right.$ C]: 1 November to 31 March). We excluded the transitional months of April and October because regional average temperatures vary between hot and cool. We generated a binary capture history containing 14 seasons with 22 weekly occasions each season. The binary capture history was thoroughly inspected and was not found to violate the assumptions of closed populations or independence between occasions and between seasons (D. MacKenzie, Proteus, pers. com).

We used the fourth parameterization in the simple multiseason model framework using the seasonal occurrence and detection in PRESENCE. Habitat use $(\psi)$ in this context was defined as the probability that ocelots will use a given site and movement in and out of that site is random (MacKenzie et al. 2018). Detection $(\rho)$ is defined as the probability of detecting an ocelot at a site, at a given occasion or season (MacKenzie et al. 2018). For model selection, we used a two-step process following methodologies described by Noigere et al. (2013), in which we first modeled detection and then used the topperforming detection covariates to derive habitat use $(\psi)$ models. Detection was modeled as a function of 15 biologically relevant models that included a drought variable (i.e., Palmer Drought Severity Index [drought: $<-1.0$; wet $>$ $1.0]$ ) and two temporal variables (between- and withinseason variable), for a total of 30 total candidate detection models (Supplementary material Table 2). We used the standard temporal models available in program PRESENCE to examine whether detection changed between survey periods (between-season) or if detection of ocelots changed from occasion to occasion during each season (within-season model). Using the top-performing detection model, we modeled habitat use patterns $(\psi)$ as a function of 11 biologically relevant candidate models based on our a priori hypotheses (Supplementary material Table 1). We assessed model fit by running 1000 bootstraps and did not consider models that failed to converge, as this may be due to overdispersion $(\widehat{c}$ $>1.0$ ) (Murphy et al. 2017). Models with $\triangle \mathrm{AIC}<2.00$ were considered to have substantial support (Burnham and Anderson 2002). Following the recommendation by Arnold (2010), we estimated $85 \%$ confidence intervals for coefficients in each top model.

\section{Results}

From May 2011 to March 2018, we recorded 640 photographic detections of ocelots during 8624 camera trap weeks. 

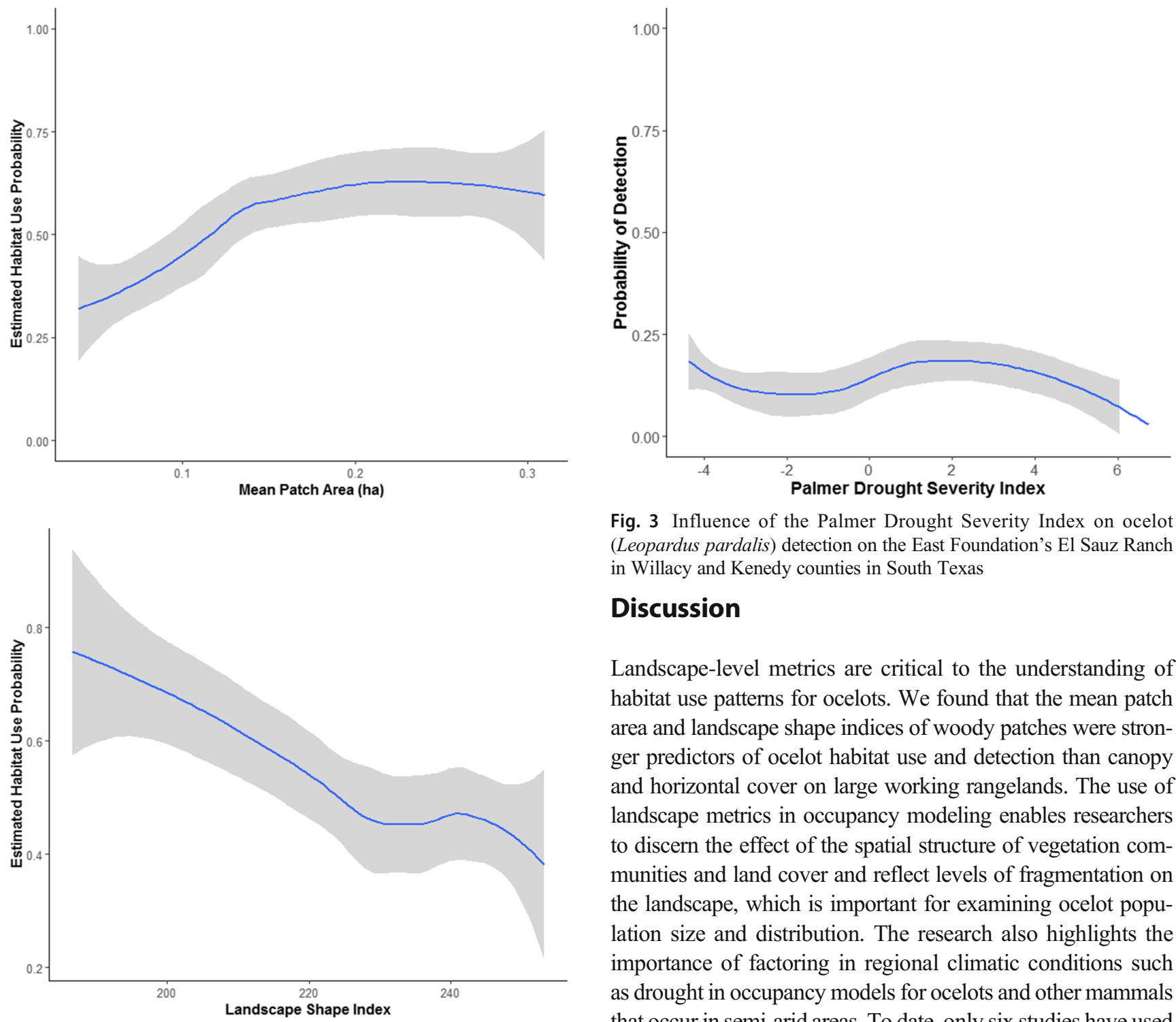

Fig. 2 Influence of mean patch area (ha) and landscape shape index of woody cover on ocelot (Leopardus pardalis) habitat use on the East Foundation's El Sauz Ranch in Willacy and Kenedy counties in South Texas

Camera stations on the ranch occurred in $55.1 \%$ woody cover with $60.7 \%$ mixed canopies (Supplementary material Table 2). Ocelot habitat use ( $\psi=0.47$; CI: $0.29-0.70)$ was strongly positively influenced by increasing mean patch area $(\beta=5.64$; CI 3.41-7.89) and negatively influenced by high shape index values $(\beta=-0.45$; CI -0.64 to -0.27$)$ (Fig. 2; Table 1$)$. Detectability of ocelots $(\rho=0.14$; CI: $0.10-0.19)$ varied between season and there was a weak negative effect of drought index ( $\beta=-0.099$; CI -0.17 to -0.02$)$ (Fig. 3; Table 1). Detection was also weakly positively influenced by increasing mean patch area $(\beta=5.26$; CI 4.25-6.27) and negatively influenced by high landscape shape index values $(\beta=$ -0.24 ; CI -0.18 to -0.31 ) (Fig. 4).

Fig. 3 Influence of the Palmer Drought Severity Index on ocelot (Leopardus pardalis) detection on the East Foundation's El Sauz Ranch in Willacy and Kenedy counties in South Texas

\section{Discussion}

Landscape-level metrics are critical to the understanding of habitat use patterns for ocelots. We found that the mean patch area and landscape shape indices of woody patches were stronger predictors of ocelot habitat use and detection than canopy and horizontal cover on large working rangelands. The use of landscape metrics in occupancy modeling enables researchers to discern the effect of the spatial structure of vegetation communities and land cover and reflect levels of fragmentation on the landscape, which is important for examining ocelot population size and distribution. The research also highlights the importance of factoring in regional climatic conditions such as drought in occupancy models for ocelots and other mammals that occur in semi-arid areas. To date, only six studies have used occupancy modeling to examine various aspects of ocelot ecology (Massara et al. 2015, 2018; Paolino et al. 2018; Wang et al. 2019; Lombardi et al. 2020a). However, only this study and Wang et al. (2019) examine ocelot habitat use over 7 years. This study contributes new information on ocelot habitat relationships in the extreme northern edge of their geographic range and on working rangelands.

From 2011 to 2018, habitat use of ocelots on El Sauz increased relative to increasing mean patch area and decreasing landscape shape index. Mean patch area is one of the strongest predictors of species occurrence or susceptibility for extirpation (Harrison 1991; Hanski et al. 1995; Crooks 2002; Michalski and Peres 2005). Bender et al. (1998) reported that forest interior species tend to decrease in population with smaller patch sizes due to habitat fragmentation. Janečka et al. (2011) reported that ocelots in South Texas do not respond well to fragmentation and often are unable to disperse between populations. Isolation of patches and subsequently 
reduced dispersal between the remaining populations has led to lower genetic diversity within the two ocelot populations in Texas. Habitat fragmentation can affect forests by not only decreasing size and area but also the shape and amount of edge available (Williams and Pearson 1997). As landscape shape index increases, patches become more irregularly shaped, and perimeter to area ratio increases, leading to a change in vegetation composition and structure (ArroyoRodríguez et al. 2008).

Our study is the opposite of Jackson et al. (2005), who found ocelots in the more isolated refuge population $(\sim$ $29 \mathrm{~km}$ south of our study area) strongly selected areas with larger shape index values and inherently more edge, indicating a greater degree of fragmentation. As compared to our study area which contains the largest undisturbed patches of woody cover occurring in coastal South Texas, $95 \%$ of the native woody cover surrounding the Laguna Atascosa NWR has been lost since the 1930s and remaining unprotected patches are continued to be fragmented by rapid urbanization and rowcrop agriculture (Tremblay et al. 2005; Leslie 2016; Tewes 2017; Lombardi et al. 2020b).

We found that ocelots on El Sauz are more likely to use large areas of woody cover, which corroborates Leonard (2016) who observed ocelots strongly selecting larger patches of woody cover in proportion with open areas in South Texas. Ocelots have also been linked to increased forested cover in Peru (Emmons 1988), Argentina (Di Bitetti et al. 2006), Brazil (Wang et al. 2019), and Texas (Shindle and Tewes 1998; Harveson et al. 2004; Haines et al. 2006; Horne et al. 2009). Like these studies, larger patches of woody cover may be linked to higher availability of preferred prey (Booth-Binczik et al. 2013; Wang et al. 2019) or greater access to potential mates. As woody patches increase in size over time, adjacent patches will merge and coalesce over time and form larger patches, which may promote ocelot habitat use and potentially assist in dispersal and movement to unperturbed habitat patches.

We were unable to find strong evidence that canopy cover or horizontal cover affected ocelot habitat use. Ocelots have been strongly linked to dense vegetation communities (> 75\% canopy cover) possibly for dense screening cover, ample prey, and secure den sites these vegetation communities may provide (Shindle and Tewes 1998; Harveson et al. 2004; Laack et al. 2005; Horne et al. 2009; Booth-Binczik et al. 2013). Heterogeneity in canopy cover $(\bar{x}=56.7,2.5-97 \%)$ and related foliage across our camera grids and areas used by ocelots may have limited our ability to discern these effects on ocelot occurrence during each survey season. Consequently, future research is needed to understand the effects these site-level metrics have on ocelots occurring in predominantly mixed canopy forests.

Drought may have negatively affected our ability to detect ocelots during this study. Although it is not clear why detection was higher during a severe drought (PDSI $<-4.0)$ than during
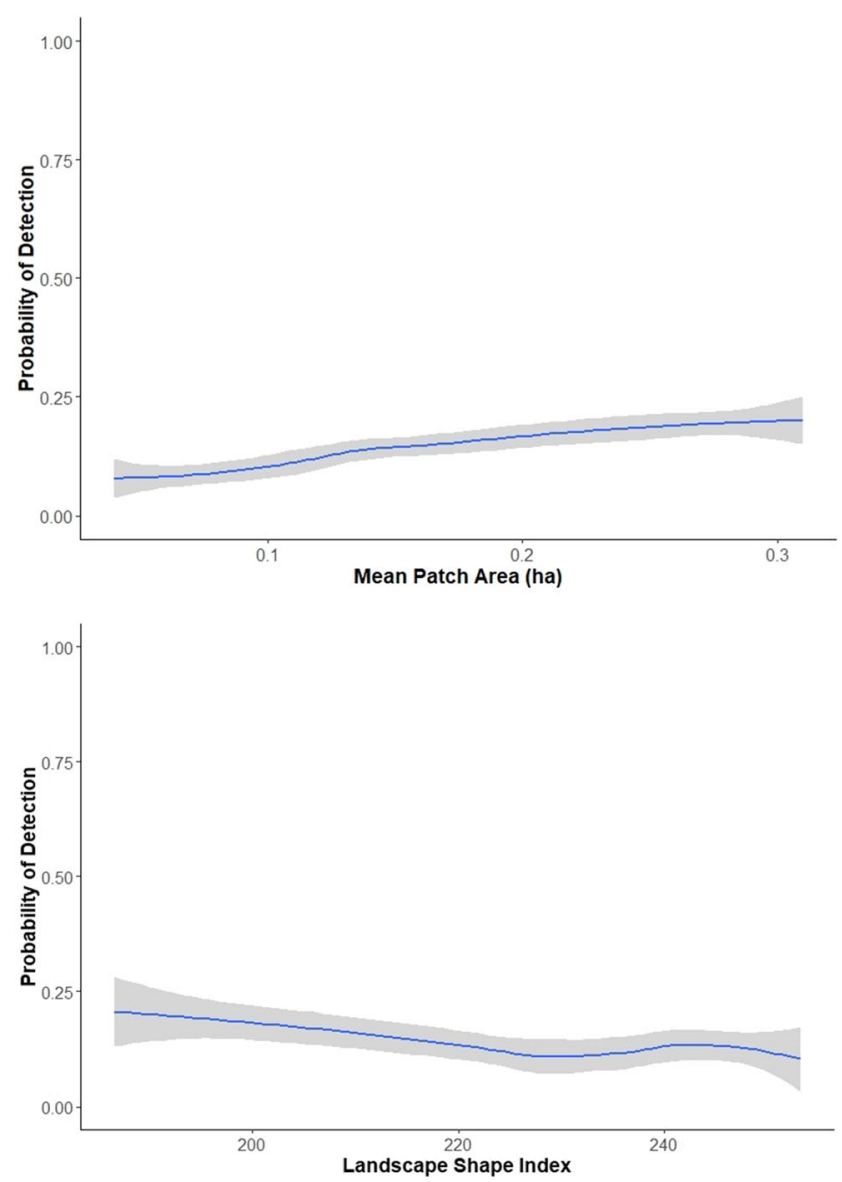

Fig. 4 Influence of mean patch area (ha) and landscape shape index of woody cover on ocelot (Leopardus pardalis) detection the East Foundation's El Sauz Ranch in Willacy and Kenedy counties in South Texas

moderate-low levels of drought $(-4.0$ to -1.0$)$. Episodic drought is a common occurrence in the semi-arid climate of South Texas (Norwine and Kuruvilla 2007). This study began during one of the most severe droughts in Texas history and ended during another period of drought. Periods of drought also likely coincide with reductions in rodent populations, which ocelots and bobcats (Lynx rufus) in South Texas rely on (Tewes and Hornocker 2007). Potential reductions in rodent populations have been linked to bobcat home ranges in the region expanding $100 \%$, which likely may also occur with ocelots (Blankenship 2000). Ocelots may be less detectable during periods of episodic drought due to increased daily movements or expansion of their home ranges to compensate for the reduction in rodent abundance (Tewes and Hornocker 2007). Future research may be warranted to understand the ecological effects of episodic drought on ocelots in South Texas.

\section{Management implications}

The contrasting results of this study compared to a previous study detailing ocelot habitat use in more fragmented areas 
underscores the importance of large private working rangelands for ocelot recovery and conservation in South Texas. Historic brush clearing 50 years ago on the southwestern edge of our study area and nearby working rangelands followed by subsequent woody cover encroachment has resulted in smaller patches of woody cover in some areas, which may not provide enough structural cover to support continued use by ocelots. However, due to the land stewardship ethic of these landowners, these patches will likely increase in size, thus increasing ocelot habitat use. Private working rangelands in South Texas will need to maintain large patches of woody cover to help facilitate ocelot habitat use and recovery in Texas.

Acknowledgments We thank the Caesar Kleberg Wildlife Research Institute, Texas A\&M University-Kingsville, and the East Foundation for logistical support. We thank the Betty and George Coates Endowed Fellowship in Habitat Research, R Barrientos, Houston Safari Club, South Texas Chapter of the Quail Coalition, and PM Plant for providing financial support for JV Lombardi. We are grateful to DI MacKenzie for his review of the raw data and consultation on analytical approaches for this study. Special thanks to past Feline Research Program members, past East Foundation staff and graduate students, and Texas Parks and Wildlife Department biologists for assistance in the field and data input. We are appreciative of LI Grassman Jr., CA Tewes, CJ Anderson, and AM Foley for reviewing and improving previous versions of this manuscript. This manuscript is 19-110 of the Caesar Kleberg Wildlife Research Institute and 035 of the East Foundation.

Funding information The East Foundation, BF Vaughn III, Tim and Karen Hixon Foundation, Brown Foundation, Travis and Bettina Mathis, Anova LNG and their parent company Exelon Generation, and Wild Cat Conservation, Inc. provided financial support for this research.

Open Access This article is licensed under a Creative Commons Attribution 4.0 International License, which permits use, sharing, adaptation, distribution and reproduction in any medium or format, as long as you give appropriate credit to the original author(s) and the source, provide a link to the Creative Commons licence, and indicate if changes were made. The images or other third party material in this article are included in the article's Creative Commons licence, unless indicated otherwise in a credit line to the material. If material is not included in the article's Creative Commons licence and your intended use is not permitted by statutory regulation or exceeds the permitted use, you will need to obtain permission directly from the copyright holder. To view a copy of this licence, visit http://creativecommons.org/licenses/by/4.0/.

\section{References}

Anile S, Devillard S, Ragni B, Rovero F, Mattucci F, Lo Valvo M (2019) Habitat fragmentation and anthropogenic factors affect wildcat Felis silvestris occupancy and detectability on Mt Etna. Wildl Biol 1

Arnold TW (2010) Uninformative parameters and model selection using Akaike's Information Criterion. The Journal of Wildlife Management 74(6):1175-1178
Arroyo-Rodríguez V, Mandujano S, Benítez-Malvido J (2008) Landscape attributes affecting patch occupancy by howler monkeys (Alouatta palliate mexicana) at Los Tuxtlas, Mexico. Am J Primatol 70:69-77

Bailey RG, Cushwa CT (1981) Ecoregions of North America. US Fish and Wildlife Service, 81/29

Bender DT, Contreras TA, Fahrig L (1998) Habitat loss and population decline: a meta-analysis of the patch size effect. Ecology 79:517533

Blankenship TL (2000) Ecological response of bobcats to fluctuating prey populations on the welder wildlife refuge. Dissertation, Texas A\&M-College Station and Texas A\&M University-Kingsville

Booth-Binczik SD, Bradley RD, Thompson CW, Bender LC, Huntley JW, Harvey JA, Laack LL, Mays JL (2013) Food habits of ocelots and potential for competition with bobcats in southern Texas. Southwest Nat 58:403-410

Burnham KP, Anderson DR (2002) Model selection and multimodel inference: a practical information theoretic approach, 2nd edn. Springer-Verlag, New York

Cardillo M, Purvis A, Sechrest W, Gittleman JL, Bielby J, Mace GM (2004) Human population density and extinction risk in the world's carnivores. PLoS Biol 2:0909-0914

Congalton GR (1991) A review of assessing the accuracy of classifications of remotely sensed data. Remote Sens Environ 37:35-46

Crooks KR (2002) Relative sensitivities of mammalian carnivores to habitat fragmentation. Conserv Biol 16:488-502

Di Bitetti MS, Paviolo A, De Angelo C (2006) Density, habitat use and activity patterns of ocelots (Leopardus pardalis) in the Atlantic Forest of Misiones, Argentina. J Zool 270:153-156

Emmons LH (1988) A field study of ocelots (Felis pardalis) in Peru. Reve d'Ecologie (la Terre et la Vie) 43:133-157

Gómez-Ramírez MA, Gutiérrez-González CE, López-González CA (2017) Ocelots thrive in a non-typical habitat of northwestern Mexico. Endanger Species Res 32:471-478

Grassman LI, Tewes ME, Silvy NJ, Kreetiyutanont K (2005) Ecology of three sympatric felids in a mixed evergreen forest in north-central Thailand. J Mammal 86:29-38

Haines AM, Tewes ME, Laack LL (2005a) Survival and cause-specific mortality of ocelots in southern Texas. J Wildl Manag 69:255-263

Haines AM, Tewes ME, Laack LL, Grant WE, Young JL (2005b) Evaluating recovery strategies for an ocelot (Leopardus pardalis) population in the United States. Biol Conserv 126:512-522

Haines AM, Janečka JE, Tewes ME, Grassman LI Jr, Morton P (2006) The importance of private lands for ocelot Leopardus pardalis conservation in the United States. Oryx 40:1-5

Hanski L, Pakkala T, Kuussaari M, Lei G (1995) Metapopulation persistence of an endangered butterfly in a fragmented landscape. Oikos $72: 21-28$

Harrison S (1991) Local extinction in a metapopulation context: an empirical evaluation. Biol J Linn Soc 42:73-88

Harveson PM, Tewes ME, Anderson GL, Laack LL (2004) Habitat use by ocelots in South Texas: implications for restoration. Wildl Soc Bull 32:948-954

Horne JS, Haines AM, Tewes ME, Laack LL (2009) Habitat partitioning by sympatric ocelots and bobcats: implications for recovery of ocelots in southern Texas. Southwest Nat 54:119-126

Hunter L (2019) Carnivores of the world 2nd edn. Princeton, NJ: Princeton University Press

IUCN 2020 IUCN red list of threatened species. Available at: http:// www.iucnredlist.org. (Accessed:10 January 2020)

Jackson VL, Laack LL, Zimmerman EG (2005) Landscape metrics associated with habitat use by ocelots in South Texas. J Wildl Manag 69: 733-738

Janečka JE, Tewes ME, Laack LL, Caso A, Grassman LI Jr, Haines AM, Shindle DB, Davis BW, Murphy WJ, Honeycutt RL (2011) Reduced genetic diversity and isolation of remnant ocelot 
populations occupying a severely fragmented landscape in southern Texas. Anim Conserv 14:608-619

Janečka JE, Tewes ME, Laack LL, Caso A, Grassman LI Jr, Honeycutt RL (2014) Loss of genetic diversity among ocelots in the United States during the 20th century linked to human-induced population reductions. PLoS One 9:e89384

Janečka JE, Davis IA, Tewes ME, Haines AM, Caso A, Blankenship TL, Honeycutt RL (2016) Genetic differences in the response to landscape fragmentation by a habitat generalist, the bobcat and a habitat specialist, the ocelot. Conserv Genet 17:1093-1108

Laack LL, Tewes ME, Haines AM, Rappole JH (2005) Reproductive life history of ocelots Leopardus pardalis in southern Texas. Acta Theriol 50:505-514

Leonard JP (2016) Home range characteristics, activity patterns, and resource selection of sympatric ocelots (Leopardus pardalis) and bobcats (Lynx rufus) and major histocompatibility complex variation in ocelots. Dissertation, Texas A\&M University-Kingsville

Leonard JP, Tewes ME, Lombardi JV, Wester DW, Campbell TA (2020) Effects of sun angle, lunar illumination, and diurnal temperature on temporal movement rates of sympatric ocelots and bobcats in South Texas. PLoS One

Leslie DM Jr (2016) An international borderland of concern: conservation of biodiversity in the Lower Rio Grande Valley. US Geological Survey, Scientific Investigations Report 2016-5078

Lombardi JV, Mengak MT, Castleberry SB, Terrell VK (2018) Natural and anthropogenic factors of Allegheny woodrat occupancy. Wildl Soc Bull 42:667-673. https://doi.org/10.1002/wsb.923

Lombardi JV, MacKenzie DI, Tewes ME, Perotto-Baldivieso HL, Mata JM, Campbell TA (2020a) Co-occurrence of bobcats, coyotes, and ocelots in Texas. Ecol Evol

Lombardi JV, Perotto-Baldivieso HL, Tewes ME (2020b) Land cover trends in South Texas (1987-2050): potential implications for wild felids. Remote Sens 12:659

MacKenzie DI, Bailey LL, Nichols J (2005) Investigating species cooccurrence patterns when species are detected imperfectly. J Anim Ecol 73:546-555

MacKenzie DI, Nichols JD, Royale JA, Pollock KH, Bailey LL, Hines JE (2018) Occupancy estimation and modeling: inferring patterns of dynamics of species occurrence, 2nd edn. Academic Press, London

Massara RA, Paschoal AM, Doherty PF Jr, Hirsch A, Chiarello AG (2015) Ocelot population status in protected Brasilian Atlantic Forest. PLoS One 10:e141333

Massara RA, Paschoal AM, Bailey LL, Doherty PF Jr, Hirsch A, Chiarello AG (2018) Factors influencing ocelot occupancy in Brazilian Atlantic Forest reserves. Biotropica 50:125-134

McGarigal KS, Cushman SA, Ene E (2015) FRAGSTATS v4: spatial pattern analysis program for categorical and continuous maps. University of Massachusetts, Amherst. http://www.umass.edu/ landeco/research/fragstats/fragstats.html

McKinney ML (2008) Effects of urbanization on species richness: a review of plants and animals. Urban Ecosyst 11:161-176

Meek PD, Fleming P, Ballard G, Banks P, Claridge AW, Sanderson J, Swann D (eds) (2014) Camera trapping: wildlife management and research vol 2. Melbourne, Australia: Csiro Publishing

Michalski F, Peres CA (2005) Anthropogenic determinants of primate and carnivore local extinctions in a fragmented forest landscape of southern Amazonia. Biol Conserv 124:383-396

Murphy AJ, Farris ZJ, Karpanthy S, Kelly MJ, Miles KA, Ratelolahy F, Rahariniaina RP, Golden CD (2017) Using camera traps to examine distribution and occupancy trends of ground-dwelling birds in northeastern Madagascar. Bird Conserv Int 1-14
Nagy-Reis MB, Nichols JD, Chiarello AG, Ribiero MC, Setz EZ (2017) Landscape use and co-occurrence patterns of neotropical spotted cats. PLoS One 12:e0168441

Navarro-López D (1985) Status and distribution of the ocelot (Felis pardalis) in South Texas. Thesis. Texas A\&I University

Noigere TM, Davis FW, Duggan JM, Crooks KR, Boydston EE (2013) Carnivore use of avocado orchards across agricultural - wildland gradient. PLOSone. https://doi.org/10.1371/journal.pone.0068025

Norwine J, Kuruvilla J (2007) The changing climate of South Texas, 1900-2100: problems and prospects, impacts and implications. CREST-RESSACA, Texas A\&M University-Kingsville

Paolino RM, Royale JA, Versiani NF, Rodrigues TF, Pasqualotto N, Krepschi VG, Chiarello AG (2018) Importance of riparian forest corridors for the ocelot in agricultural landscapes. J Mammal 99: 874-884. https://doi.org/10.1093/jmammal/gyy075

Perotto-Baldivieso HL, Wu XB, Peterson MJ, Smeins FE, Silvy NJ, Schwertner TW (2011) Flooding-induced landscape changes along dendritic stream networks and implications for wildlife habitat. Landsc Urban Plan 99:115-122

Sanderson EW, Jaiteh M, Levy MA, Redford KH, Wannebo AV, Woolmer G (2002) The human footprint and the last of the wild: the human footprint is a global map of human influence on the land surface, which suggests that human beings are stewards of nature, whether we like it or not. BioScience 52:891-904

Satter CB, Augustine BC, Harmsen BJ, Foster RJ, Sanchez EE, Wultsch C, Davis ML, Kelly MJ (2019) Long-term monitoring of ocelot densities in Belize. J Wildl Manag 83:283-294

Scott M, Davis FW, Mcghie RG, Wright RG, Estes J, Scott JM, Davis IFW, Mcghie RG, Wright RG, Groves C (2001) Nature reserves: do they capture the full range of America's biological diversity? Ecol Appl 11:999-1007

Shindle DB, Tewes ME (1998) Woody species composition of habitats used by ocelots (Leopardus pardalis) in the Tamaulipan Biotic Province. Southwest Nat 43:273-279

Singh R, Qureshi Q, Sankar K, Krausman PR, Goyal SP (2014) Population and habitat characteristics of caracal in semi-arid landscape, western India. J Arid Environ 103:92-95

Tewes ME (2017) Clinging to survival in the borderlands: ocelots face dwindling habitat and growing isolation. The Wildlife Professional Sept/Oct: $26-29$

Tewes ME, Hornocker MG (2007) Effects of drought on bobcats and ocelots. In: Fulbright TE, Hewitt DG (eds) Wildlife science: linking ecological and management applications. CRC Press, Boca Raton, pp 123-138

Tremblay TA, White WA, Raney JA (2005) Native woodland loss during the mid-1900s in Cameron County. Tex Southwest Nat 50:479-482

Wang B, Rocha DG, Abrahams MI, Antunes AP, Costa HC, Gonçalves AL, Spironello WR, de Paula MJ, Peres CA, Pezzuti J, Ramalho E, Reis ML, Carvalho E Jr, Rohe F, MacDonald DW, Tan CKW (2019) Habitat use of the ocelot (Leopardus pardalis) in Brazilian Amazon. Ecol Evol 9:5049-5062

Williams SE, Pearson RG (1997) Historical rainforest contractions, localized extinctions, and patterns of vertebrate endemism in the rainforests of Australia's wet tropics. Proc R Soc B 264:709-716

Zemanova MA, Perotto-Baldivieso HL, Dickins EL, Gill AB, Leonard JP, Wester DB (2017) Impact of deforestation on habitat connectivity thresholds for large carnivores in tropical forests. Ecol Process 6: 21. https://doi.org/10.1186/s13717-017-0089-1

Publisher's note Springer Nature remains neutral with regard to jurisdictional claims in published maps and institutional affiliations. 